\title{
Escrita e tradução
}

\section{Writing and translation}

Angela Leite Lopes ${ }^{1}$ 


\section{Resumo}

A proposta deste artigo é abordar a tradução como escrita, algo que lida com a criação e o pensamento. Partindo das noções de autoria e originalidade tais como analisadas por Walter Benjamin e Maurice Blanchot, o presente artigo comenta exemplos específicos extraídos da experiência da autora com tradução para teatro e muito especialmente textos de Valère Novarina, Pierre Corneille, Nelson Rodrigues e Plínio Marcos.

Palavras-chave: Tradução; escrita; autoria; teatro
The purpose of this article is to approach translation as writing, dealing with creation and thinking. Parting from the notions of authorship and originality as Walter Benjamin and Maurice Blanchot have analysed, the ensuing article comments specific examples from the author's translation experience for theatre. These examples include texts of Valère Novarina, Pierre Corneille, Nelson Rodigues and Plínio Marcos.

Keywords: Translation, writing; authorship; theatre

E-ISSN: 2358.6958

1 Professora titular aposentada da Escola de Belas da Universidade Federal do Rio de Janeiro (UFRJ). angelall58@gmail.com 
"Será que sabemos tudo o que devemos aos tradutores e, mais ainda, à tradução? Sabemos mal"2 (Blanchot, 2003, p.9). Assim Maurice Blanchot começa seu "Traduzir", texto no qual vai comentar as considerações de Walter Benjamin (2011) no clássico "A tarefa do tradutor".

De fato, sabemos muito mal, ainda hoje, tudo o que devemos à tradução e talvez até no fundo nem saibamos ao certo que tratamento dar a ela. Prova disso é a maneira como a tradução é referida, tanto no âmbito acadêmico, em que consta geralmente da área técnica, quanto no âmbito artístico, em que chega algumas vezes até a ser omitida.

Traduzir não é apenas passar de um idioma para outro. O ato de traduzir é da ordem do pensamento, conforme procurei mostrar em Traduzindo Novarina - cena, pintura e pensamento (Lopes, 2017). ${ }^{3}$ E se configura como uma forma muito específica de escrita. Como tão bem colocou Maurice Blanchot (2003, p.10):

se, com ou sem razão, ainda se costuma dizer: aqui estão os poetas, ali os romancistas, e, sim, também os críticos, todos responsáveis pelo sentido da literatura, é preciso incluir no mesmo rol os tradutores, escritores da mais rara estirpe, e realmente incomparáveis. ${ }^{4}$

Ora, para o senso comum, o que determinaria o estatuto de escrita - e digo escrita como diria criação - seria a noção de originalidade. Não sendo o tradutor o inventor da obra, a autoria lhe seria assim negada ou subtraída. Mas Maurice Blanchot (ibid., p.12) vai considerar que é nesse contexto específico que reside o ato criador próprio à tradução.

O tradutor é um escritor de singular originalidade, precisamente onde parece não reivindicar originalidade alguma. Ele é o secreto senhor da diferença das línguas, não para aboli-la mas para utilizá-la com o fito de despertar, na sua língua, por mudanças violentas ou sutis que ela lhe traz, uma presença daquilo que há de diferente, originalmente, no original. ${ }^{5}$

Trata-se, portanto, de uma forma de experiência muito particular, conforme sugere Walter Benjamin ao enfatizar que o tradutor não deve procurar adequar as características da língua de partida às da língua de chegada. A grande contribuição do tradutor enquanto escritor é fazer com que se escute uma língua estrangeira dentro da sua própria língua.

Nossas versões, mesmo as melhores, partem de um falso princípio; elas pretendem germanizar o sânscrito, o grego, o inglês, em vez de sanscritizar o alemão, helenizá-lo, anglicizá-lo. [...] O erro fundamental do tradutor é petrificar o estado

\footnotetext{
2 Savons-nous tout ce que nous devons aux traducteurs et, plus encore, à la traduction? Nous le savons mal (Blanchot, 1971, p.69).

3 Resultado da pesquisa de pós-doutorado desenvolvida em 2012-2013 no Programa de Pós-graduação em Filosofia da PUC-Rio, sob a supervisão de Luiz Camillo Osorio.

4 si l'on continue de dire à tort ou à raison: il y a ici les poètes, là les romanciers, voire les critiques, tous responsables du sens de la littérature, il faut compter au même titre les traducteurs, écrivains de la sorte la plus rare, et vraiment incomparables (Blanchot, 1971, p.69).

5 Le traducteur est un écrivain d'une singulière originalité, précisément là où il paraît n'en revendiquer aucune. Il est le maître secret de la différence des langues, non pas pour l'abolir, mais pour l'utiliser, afin d'éveiller, dans la sienne, par les changements violents ou subtils qu'il lui apporte, une présence de ce qu'il y a de différent, originellement, dans l'original (id., ibid., p.71).
} 
em que se encontra por acaso sua própria língua, em vez de submetê-la à impulsão violenta que vem de uma linguagem estrangeira (Benjamin, apud Blanchot, 2003, p.13). ${ }^{6}$

A tradução, portanto, é uma das maneiras de se explorar a escrita - o que equivale a dizer de se explorar a língua. Não se trata de compreender um texto numa língua determinada e expressá-lo em outra. Trata-se de ir escrevendo por dentro de outra escrita, tecendo um texto com os fios de outro.

\section{A teia Novarina}

Até porque nem sempre é a compreensão o que uma obra persegue. Melhor dizendo, muitas vezes a obra coloca em xeque justamente a noção usual, padronizada, de compreensão. E isso pode acontecer de forma mais ou menos radical.

Vou relatar aqui algumas experiências que tive ao traduzir textos nos quais a noção de compreensão era absolutamente problematizada e pedia para ser reinventada. Refiro-me especificamente à obra do artista franco-suíço Valère Novarina e, muito especialmente, a $O$ animal do tempo e $A$ inquietude, que traduzi para a cena em 2007 e 2002, respectivamente, bem como, mais recentemente, agora em 2019, O monólogo de Adramelech. ${ }^{7}$

Meu primeiro contato com o universo de Novarina foi em 1999 com a tradução de Carta aos atores e Para Louis de Funès, que podem ser colocados na categoria de ensaios: textos com um propósito bem claro conduzido por um raisonner/résonner, ${ }^{8}$ ou seja, um raciocínio em que a reverberação sonora é parte ativa do pensamento. Para isso, Novarina lança mão de neologismos e mexe por vezes na construção sintática das frases. Mas havia ali de todo modo algo a ser compreendido, em sua acepção mais usual, algo que se costuma chamar de sentido e que guiava a escrita da tradução.

Em 2002, entretanto, ao me deparar com L'Inquiétude para a realização das legendas que acompanhariam o espetáculo apresentado pelo ator francês André Marcon no Brasil, tive minha primeira experiência de traduzir um texto que fugia à compreensão. É esta a síntese do que foi essa empreitada: traduzir algo que escapa, propositalmente, à compreensão. "O homem entra pela segunda última vez" é a rubrica que abre o texto, que começa assim:

\footnotetext{
6 Nos versions, même les meilleures, partent d'un faux prinicipe; elles prétendent germaniser le sanscrit, le grec, l'anglais, au lieu de sanscritiser l'allemand, de l'helléniser, de l'angliciser. [...] L'erreur fondamentale du traducteur est de figer l'état où se trouve par hasard sa propre langue, au lieu de la soumettre à l'implusion violente qui vient d'un langage étranger (Blanchot, 1971, p.72).

7 L'Animal du temps foi traduzido em 2007 para a montagem dirigida por Antonio Guedes com atuação de Ana Kfouri, apresentada no Sesc Copacabana, Rio de Janeiro; L'Inquiétude foi traduzida em 2002 para a legendagem do espetáculo de André Marcon que fez turnê no Brasil, se apresentando no Festival de Curitiba, na reabertura do Teatro Maison de France no Rio de Janeiro e também em São Paulo. Esse texto foi posteriormente montado com direção de Thierry Trémouroux e atuação de Ana Kfouri, tendo estreado no Sesc Copacabana, durante o festival "Novarina em cena", no Rio de Janeiro, em julho de 2009. Le Monologue d'Adramélech foi traduzido em 2019 para ser montado por Antonio Guedes com Sergio Machado, em local e data ainda a definir.
}

8 Raisonner: raciocinar; résonner: ressoar. Sobre essa relação, cf. Lopes, 2017, p.66-70. 
Então sentei e disse às pedras: A ação é maldita. Uma serenata me acordava todas as tardes matinais e eu já caía ali de pé a noite inteira até o ruído branco dos feios cantos da alvorada. Cada hora me dizia que eu era João Mancada (Novarina, 2007b, p.35). ${ }^{9}$

Gosto muito especialmente de citar esse trecho inicial de $A$ inquietude. ${ }^{10}$ Acho que ele deixa ouvir com muita clareza uma das características principais da escrita de Novarina, que é a solidez estrutural da partitura que ele compõe. Para o ato de traduzir, isso significa que o que deve ser feito é acompanhar as palavras em seu encadeamento rítmico e sonoro. Correndo o risco de me repetir, insisto que não se trata de ler o texto, compreendê-lo e depois traduzi-lo. Há que ir compondo, justamente, com as palavras que ali se apresentam e criando uma escuta. Não à toa, Novarina abre seu Carta aos atores afirmando: "Escrevo com os ouvidos. Para atores pneumáticos" (Novarina, 1999, p.7, grifo meu). ${ }^{11}$ É nessa disposição que o tradutor tem que se colocar também.

No exemplo acima, a partitura logo se impõe à escrita e à escuta. Mais do que o esboço da imagem do personagem, é uma cadência que vai sendo armada. Já de cara, o próprio nome - João Mancada - reitera essa cadência, que vai se instaurando de fato no escandir das sílabas e na alternância de assonâncias e de rimas. Nesse trecho específico, há a felicidade de se poder manter praticamente o mesmo jogo do original e terminar as duas últimas frases com as rimas: moches - Cloche; alvorada - Mancada. E de ter em Mancada um equivalente para qui Cloche tanto no sentido semântico quanto dramático. Sim, porque, além de uma ridícula estranheza expressa nesses termos, há também e principalmente a sugestão de um tipo de andar, de um jeito de corpo, que é da ordem da ação e do contracenar. Mas que não precisa - nem deve - ser seguida ao pé da letra; apenas reitera algo da ordem de uma desestabilização constante e estrutural.

O exemplo evidencia assim o fato de que o tratamento dado ao texto é realmente o de uma tessitura, e seu desenrolar mais parece um desfiar, numa espécie de vigorosa autofagia. Não há referências, ou muito poucas, que forneçam um rumo ao leitor ou ao espectador. O texto opera por uma construção em negativo na qual o que vai interessando e prendendo a atenção é a profusão de sons, ritmos, imagens que se formam e se desfazem. Na verdade, o interesse está na descoberta da escuta, das possibilidades inéditas e inesperadas que se vão criando ali. Em determinados momentos, entretanto, essa falta de referencial pode deixar o tradutor numa encruzilhada. Se para o leitor ou o espectador, alguns sentidos podem ficar em aberto, o tradutor tem que fazer uma opção. Mas nem sempre é possível discernir de imediato qual seria a melhor... Foi o caso de la lumière nuit, frase fetiche de Novarina sobre a

9 (Entrée de l'homme pour la deux dernière fois). Alors je me suis assis et j'ai dit aux pierres: L'action est maudite. Une sérénate me réveillait tous les soirs matinaux et j'en tombais debout la nuit jusqu'au son blanc des aubades moches. Chaque heure me disait que j'étais Jean qui Cloche (Novarina, 1993, p.7).

10 De fato, recorro muitas vezes a esse trecho quando escrevo sobre meu trabalho de tradução da obra de Novarina (cf. em especial Lopes, 2017, p.51; Lopes, 2018, p.215). Como a tradução é o eixo do meu trabalho, será inevitável retomar em diversas ocasiões aqui citações e considerações que constam em outras análises minhas, fazendo sempre referência a elas.

11 J'écris par les oreilles. Pour les acteurs pneumatiques (Novarina, 2007a, p.9). 
tradução da qual também já tratei em diversas ocasiões. ${ }^{12}$ Retomo aqui muito brevemente um dos meus relatos.

Foi com $A$ inquietude que tive o primeiro contato com la lumière nuit, no trecho a seguir:

Cinq. «La lumière nuit. La lumière nuit. La-lumière-nuit.» Elle nuisait vers cinquante-sept, vers soixante, vers La Roche-sur-Foron. On se souvient sur Foron encore de moi là-bas au bord; on m'y appelle encore souvent parfois l'Enfant des Aurtruis, celui qui passa en manches courtes, en bonds souvent splendides, le long de ses trous nés non loin (Novarina, 1993, p.12-13). ${ }^{13}$

Eu não tinha justamente nenhum referencial que me indicasse como traduzir nuit na frase la lumière nuit, conforme relatei em "Cesura e suspensão na cena de Novarina" (Lopes, 2011, p.37):

O seu sentido me pareceu por demais oculto e não consegui chegar a uma tradução satisfatória: a simples repetição das palavras francesas, a luz noite, não me convencia e à repetição de "la lumière nuit" seguia "elle nuisait", o que parecia indicar a importância do sentido do verbo nuire [ser nocivo a], pelo qual acabei optando.

Só fui encontrar uma tradução satisfatória para essa frase sete anos depois, quando traduzi Vocês que habitam o tempo para a montagem dirigida por Claude Buchvald. ${ }^{14}$

\begin{abstract}
A Criança das cinzas - No dia seguinte à minha morte, enojado de ter que viver sem corpo, eu anunciava à noite sem pão, que a luz estava em noite entre nós. Vendo que a luz noitinha, eu lhe dizia: "Luz seja!" Mas ela não iluminou; pois a luz estava sozinha na sua luz, não tendo de repente nada a não ser ela para iluminar (Novarina, 2009b, p.205, grifo meu). ${ }^{15}$
\end{abstract}

Volto ao meu relato em "Cesura e suspensão na cena de Novarina": "acredito que foi o tempo verbal, no passado em função da narrativa, que facilitou o meu acesso a essa formulação" (Lopes, 2011, p.38). Não foi, portanto, uma interpretação que determinou a escolha, mas o próprio fluxo da escrita. Um pouco antes, eu havia trocado e-mails com Novarina, que apenas me aconselhou: "recupera a noite, se puder" (Lopes, 2011, p.38).

O espetáculo $A$ inquietude, de Ana Kfouri e Thierry Trémouroux, que estreou também durante o "Novarina em cena", contou então com a nova versão do texto, tendo a seguinte tradução para o trecho citado mais acima em francês:

\footnotetext{
12 Em especial: Lopes, 2009b, p.37-38; e Lopes, 2017, p.96-97 (no capítulo 4. La lumière nuit: língua, pensamento, tradução).

13 Cf. a tradução desse trecho mais adiante.

14 Vous qui habitez le temps foi traduzida em 2008 para a montagem dirigida por Claude Buchvald com alunos-atores da UFRJ, da Unirio e da Universidade Paris 8 e se apresentou no Teatro Glauce Rocha no Rio de Janeiro em 2009 durante o festival "Novarina em cena".

15 L'Enfant des Cendres - Le lendemain de ma mort, dégoûté d'avoir à vivre sans corps, j'annonçai à la nuit sans pain, que la lumière était en nuit parmi nous. Voyant que la lumière nuit, je lui dis: «Lumière soit!» Mais elle n'éclaira pas; car la lumière, était toute seule dans sa lumière, n'ayant soudain plus rien que elle à éclairer (Novarina, 1989, p.85).
} 
Cinco. "A luz noitinha. A luz noitinha. A-luz-noitinha". Ela noitava por volta de cinquenta e sete, por volta de sessenta, por volta de Rocha-no-Foron. Ainda se lembram de mim em Foron ali pela beira; ainda me chamam às vezes muitas Filho dos Outrens, aquele que passa de mangas curtas, em saltos muitas vezes esplêndidos, ao longo dos seus buracos nascidos tão longe (Novarina, 2007b, p.37). ${ }^{16}$

Retomei aqui esse relato resumido por ser um exemplo eloquente do desafio que pode se apresentar nesse tipo de empreitada. O caso de a luz noitinha é emblemático por se tratar de uma frase que aparece em praticamente todos os textos de Novarina, assim como em sua obra plástica. Essa repetição acabou formando um rastro que foi sendo descoberto e que levou ao que se costuma chamar de solução - e por que não?, já que, de fato, o que se tem aqui é mesmo da ordem do enigma. Que por vezes é bem imbricado, como no caso de $O$ monólogo de Adramelech, que começa assim:

Adramelech! Adramelech! (Ele entra) Satanés de marmilhares de bilhões de aparentes! Seiscentos e noventa mil milhões de trilhares de bilhões! Esse Adramelech, seu labor está no auge. Adramelech!... Senhor? Te formei com limo. E aonde vou? Bem abrigado dentro do teu paletó de madeira roer tua estirpe logo represada. Sim Diabo, lá vou eu com certeza rapidinho. Falo assim com aquele que estaria me secando e me espionando pela luneta. Os nove quartos de nossas vidas são comidos em horas estúpidas de estâncias de estácias de vai-e-vem! Levantaremos nossos braços e sua cabeça vai cair. Ah estou bem mal contente de minha vida de trajeto de estações ridículas! Minha cabeça é triangular demais, não redonda o bastante na minha ideia: meus braços tudo bem, não muito longos também e me faltam oito para chegar a dez (Novarina, 2019). ${ }^{17}$

Gosto dos inícios, do pontapé inicial de um texto, principalmente quando se destina à cena, porque ali logo vai se instaurando a tal da partitura. Assim como em $A$ inquietude ou em $O$ animal do tempo, que também narra as peripécias do João, $O$ monólogo de Adramelech não oferece nenhum referencial, a não ser os do próprio mito, ${ }^{18}$ que são muito livremente recriados.

Prende ele, chefe, ele resiste e nega chispar. Adramelech! Mmmmm? te formei com limo, não gostou? Sozinho, ele fica entediado, senhor. Tinha que dotar esse babaca de um saxus. Vamos plantar alguém pertinho desse alifafe. Adramelech, insone, eis aqui teu saxus. Obrigado. Mais uma irmã. Obrigado. Te enfio uma irmã para que você pie menos. Bom dia senhora homeza, furada (Novarina, 2019). ${ }^{19}$

\footnotetext{
16 Acabei criando com "noitava" um neologismo que não existe no original. Em nova oportunidade, pretendo repetir mesmo "noitinha", já que manter exatamente o que está no original é impossível.

17 Adramélech! Adramélech! (II entre) Satanés marmillards de billions d'apparents! Six cent quatre-vingt-dix mille millions de trilliards de billions! L’Adramélech, son labeur est à son comble. Adramélech!... Sire? Je t'ai formé au limon. Et où je vais? Bien à l'abri sous ton paletot de planches ronger ta souche vite éclusée. Oui Diable, j'y vais c'est sûr à toute vitesse. Ainsi je parle à celui qui me lorgnerait et m'épierait par la lunette. Les neuf quarts de nos vies sont mangés en heures stupides de stances de staces de va-et-vient! Nous lèverons nos bras et votre tête va tomber. Ah je suis mal content de ma vie de trajet à stations ridicules! Ma tête est trop triangulaire, pas assez ronde à mon idée: mes bras sont bons, pas assez longs et m'en manque huit pour en faire dix (Novarina, 2009a, p.7-8).

18 Adramelech é uma deidade mencionada na bíblia judaica. É também o grande embaixador do Inferno, responsável pelo guarda-roupa do soberano dos demônios, presidente do alto conselho dos diabos, além de muito sedutor.

19 Arrêtez-le, chef, il résiste et nie galoper. Adramélech! Mmmmm? je t'ai formé au limon, ça te plaît pas? Seul, il s'ennuie, sire. Fallait le doter d'un saxus, le con. Plantons quelqu'un auprès de ce polochon. Adramélech, insomniaque, voilà ton saxus. Merci. Plus une soeur. Merci. Je te flanque d'une soeur pour que tu piaffes moins. Bonjour madame l'homesse, la percée (Novarina, 2009a, p. 11).
} 
Essa escrita enigmática tem, portanto, sua chave dentro dela mesma. É como se fosse uma lógica singular. Não à toa, Novarina criou o termo logodinâmica ${ }^{20}$ para falar da operação que move seu pensamento: algo que seria da ordem do movimento e da razão e no qual um não pode ser compreendido sem o outro. Operação que se estende por toda sua produção artística. Com esses exemplos específicos, o importante é perceber que o ato de tradução é uma escrita dentro de outra escrita, sempre, em se tratando de textos que querem refundar o que significa compreender, como é o caso dos trechos citados até aqui, ou não.

\title{
A trama de versos e rimas
}

Outra das minhas experiências de tradução que também expõe a diferença entre, por um lado, o entendimento de que se deve transmitir aquilo que o texto tem a dizer e, por outro, o de trazer para outra língua a operação de linguagem efetuada pelo original, foi com O Cid, de Pierre Corneille (1963), em 1991, para um ciclo de leituras. ${ }^{21}$ Escrita na França no século XVII, a peça segue alguns cânones que, por terem se tornado obsoletos há centenas de anos, parecem ser absolutamente dispensáveis na atualidade.

De fato, há algumas traduções de obras de autores do chamado classicismo francês que optaram por abolir a principal convenção que conduz a escrita desses textos: os versos rimados e, mais especificamente, os alexandrinos, versos de doze pés considerados a fina flor da expressão da língua francesa. Foi o caso da tradução de Millôr Fernandes (Racine, 1986), que optou pelos versos brancos na Fedra de Racine (1962) montada no Brasil nos anos 1980, com direção de Augusto Boal e Fernanda Montenegro no papel-título, cujo início cito aqui:

\author{
Hipólito \\ Está decidido, bom Terâmeno, eu parto; \\ Abandono Tresena, esta cidade amada. \\ Assaltado por dúvidas terríveis \\ Já me envergonho do ócio em que vivo. \\ Há mais de seis meses longe de meu pai, \\ Não sei o destino desse rosto querido, \\ Ignoro os lugares que o podem esconder. \\ (Fedra, Ato I, Cena I) ${ }^{22}$
}

No programa do espetáculo, Millôr justifica sua opção:

a peça, em português, preservaria mais sua autenticidade se abandonássemos a forma rimada e alexandrina (tão emprenhada nos ouvidos franceses) pelo verso branco. Compensando a perda da rima pela clareza da ordem direta, ganhando na reprodução do sentido exato das falas, no ritmo, na correspondência poética, no

\footnotetext{
20 Ver a esse respeito Lopes, 2017, p.49-70 (capítulo 2, Logodinâmica).

21 Promovida pelo RioArte, a leitura aconteceu no Espaço Cultural Sérgio Porto, no Rio de Janeiro, com direção de Jacqueline Laurence, tendo Edson Celulari no papel-título e Déborah Evelyn no papel de Ximena.

22 Hippolyte - Le dessein en est pris: je pars, cher Théramène, / Et quitte le séjour de l'aimable Trézène. / Dans le doute mortel dont je suis agité, / Je commence à rougir de mon oisiveté. / Depuis plus de six mois éloigné de mon père, / J'ignore le destin d'une tête si chère; / J'ignore jusqu'aux lieux qui le peuvent cacher. (Phèdre, Acte I, Sc. 1)
} 
maior rendimento dramático por parte dos atores e maior facilidade de recepção por parte do público. Ponto (Racine, 1986, p.10).

Segundo o tradutor, então, houve necessidade de compensar a perda da rima, estabelecendo um contraponto com a clareza. Independente da beleza do resultado da tradução de Millôr Fernandes, o que ele está perseguindo é a facilidade e reiterando o compromisso com o sentido exato. Mas o que seria o sentido exato de uma peça, ainda mais sendo essa peça a Fedra de Racine? Como Millôr tão bem observa, os versos em alexandrino estão de fato emprenhados nos ouvidos franceses, e é essa experiência que o leitor ou o espectador francófono procura no contato com essa tragédia. Nunca é demais lembrar que não se trata mais do mito de Fedra. Trata-se de um embate que envolve honra e paixão, ou seja, um conflito de forças que está presente e inscrito na própria fala da peça pela relação entre a coação da métrica e a expansão da palavra.

Por isso fiz questão de abrir a edição da minha tradução de O Cid com a seguinte nota:

Não concebo um $C i d$ sem rimas. Numa peça em versos, rimada, o espectador vai sendo levado o tempo todo pela expectativa, pela surpresa ou pelo previsível - há um jogo que se arma na linguagem ao mesmo tempo que na trama em si (Corneille, 2013, p.7).

E continuei ${ }^{23}$ defendendo essa premissa no prefácio intitulado "O tempo em verso" (Lopes, 2013, p.11):

$\mathrm{O}$ verso instaura uma experiência de tempo. Pela métrica, ele incorpora o tempo no sentido da fala. Dizer o verso é antes de mais nada compreender e empreender noções de ritmo, andamento, duração. É falar - entregar-se ao fluxo da vida -, e fazer ouvir o silêncio - compasso da eternidade.

Ademais - e isso me parece de suma importância, por isso retomo essa mesma observação feita acima sobre a Fedra de Racine -, sendo O Cid uma lenda, o que interessa na peça de Corneille não é a história propriamente dita e sim, basicamente, a relação entre a adaptação feita por ele no intuito de expor os conflitos de valores da sua época e o falar/cantar do francês em alexandrinos. Grande parte do interesse em traduzir O Cid de Corneille está, portanto, em se aproximar dessa sua escrita.

De um certo ponto de vista contemporâneo, esse tipo de verso rimado pode parecer limitador para a atuação. Mas o que se esquece é que versos trazem a marca de uma estreita relação com o corpo. Basta lembrar que são contados em pés - e não em sílabas -, remetendo ao escandir dos passos que, na Antiguidade, pontuavam as sílabas tônicas. É, portanto, o corpo todo que diz o verso! Há também outra objeção que se faz ao verso rimado, alegando artificialidade, algo só concebível ao se considerar que a cena é da ordem da naturalidade - que é tudo o que ela não é, mesmo quando se presta a alguma performance naturalista. ${ }^{24} \mathrm{O}$ verso tem, portanto, como

23 De 1995 a 1997, fui pesquisadora visitante com bolsa da Faperj no Curso de Mestrado em Teatro da Unirio, desenvolvendo o projeto "O tempo no teatro".

24 Cf. Lopes, 2000. 
uma de suas caraterísticas principais trazer para o texto uma extrema fisicalidade, pois há toda uma dinâmica que só se estabelece com o controle extremo do corpo e da respiração. Volto a alguns trechos do meu prefácio:

Considero essa relação privilegiada do verso [...] de grande atualidade por permi-
tir uma nova dimensão da palavra em cena, ligando-a diretamente ao jogo do ator,
fazendo dele o principal agente do tempo, mais até do que a própria narrativa,
do que a progressão de épocas e episódios no interior do enredo da peça. [...] O
verso é também uma forma de pôr em cena o engajamento corporal exigido pela
fala [... e pelo] respirar: inspirar, transformar o sopro em sentido, dando-lhe vigor,
alcance, direção. Respiração que imprime um ritmo, interno e externo, que por
sua vez pede e produz a escuta [...]. Esse canal é determinado por um sentido que
vai se depreendendo do jogo que a palavra ajuda a estabelecer em cena. Não há,
portanto, relação predeterminada, não há, portanto, identidade, [...] então também
não há naturalismo nem psicologismo possiveis (Lopes, 2013, p.11-12).

Penetrar a escrita de Corneille, portanto, foi o grande desafio da tradução de $O$ Cid. O trabalho consistiu em acompanhar as rimas, mas foi imprescindível transformar a métrica. Conforme comentei um pouco acima, os alexandrinos são considerados a fina flor da língua francesa, língua com pouca variação tônica, basicamente oxítona, o que faz com que seus versos acabem ficando mais longos, posto que a acentuação costuma cair na última sílaba das palavras. Já o português - com suas variações tônicas e com palavras cujas sílabas finais se fundem em certos casos com as primeiras sílabas das palavras seguintes - é uma língua mais concisa. Optei então por decassílabos, que são também versos clássicos, por assim dizer, do nosso idioma.

É importante fazer aqui uma ressalva. No início deste artigo, defendi a proposta de Walter Benjamin, segundo a qual a tradução deveria estrangeirizar a língua de chegada. Dentro desse espírito, por que não manter os alexandrinos na tradução de O Cid? A escolha pelo decassílabo se deu porque seria preciso inserir muito mais palavras do que o necessário para se chegar aos doze pés, devido às características da língua portuguesa. O estilo acabaria se tornando pesado, atrelando seu aspecto poético a um rebuscamento que seria justamente o contrário daquilo a que a escrita de Corneille se propõe. Algumas traduções mais antigas que fizeram essa opção acabaram sendo responsáveis por se associar a opção por versos rimados a um certo tipo de rebuscamento pedante, resultando em textos verbosos, em suma, em literatice. $E$ isso se torna ainda mais grave porque esses versos são feitos para ser ditos, para ser parte do jogo da cena.

A partitura da peça foi então sendo composta no jogo que se arma na fala com a métrica e a rima. Cito aqui como exemplo um trecho inicial do célebre monólogo de Dom Diego, pai de Rodrigo, que se lamenta após ter sido esbofeteado pelo Conde de Gormás, pai de Ximena, a jovem com quem Rodrigo está prestes a se casar:

\footnotetext{
Ó raiva! ó desespero! ó velhice inimiga!

Terei vivido tanto só para essa intriga?

Terei envelhecido como bom soldado,

Para ver num só dia meus louros murchados?

Meu braço que inspira respeito a toda Espanha,

Meu braço que já lhe deu vitórias tamanhas,

Que tantas vezes manteve o rei em seu trono,
} 
Trai a minha causa, e nada faz por seu dono?

(O Cid, Ato I, Cena 4) $)^{25}$

Mas há na peça dois momentos específicos em que essa métrica sofre variações. São as também famosas estâncias - respectivamente de Rodrigo e da Infanta. Essas estâncias têm uma métrica própria, de versos alternados, conforme mostra o trecho inicial da estância de Rodrigo:

Meu coração sucumbe à dor

De um golpe tão imprevisto quanto mortal,

Pobre vingador de uma querela leal,

Infeliz objeto de desleal rigor,

Eu permaneço imóvel e minh'alma aflita

Morre dessa desdita.

Perto de ver meu fogo respondido,

Ó Deus, a estranha pena!

Nessa afronta meu pai é o ofendido,

E o ofensor o pai de Ximena!

(O Cid, Ato I, Cena 6) $)^{26}$

Como não poderia deixar de ser, rima e métrica vão conduzindo o desfiar da trama. O Cid se estrutura numa repetição que beira a obsessão: Ximena, embora ame Rodrigo, se nega a com ele se casar e, mais ainda, coloca como objetivo de sua existência que ele pague com a vida a morte do pai dela. Rodrigo, que se torna a partir de todo esse infortúnio o grande herói que, por ter vencido os mouros, passa a ser chamado de Cid, só aceita receber o castigo das próprias mãos de Ximena. O conflito entre honra e amor enreda os personagens da peça não deixando nenhuma saída, já que não podem e não querem renunciar a nenhum dos lados do dilema. Só lhes resta então esse apaixonado duelo, que se inscreve também nos próprios versos:

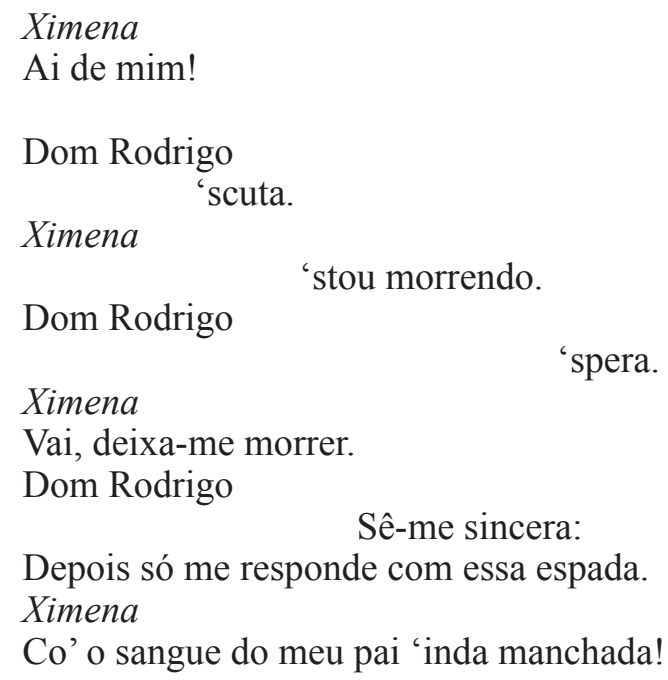

25 O rage! ô désespoir! ô vieillesse ennemie! / N'ai-je donc tant vécu que pour cette infamie / Et ne suis-je blanchi dans les travaux guerriers / Que pour voir en un jour flétrir tant de lauriers? Mon bras, qu'avec respect toute l'Espagne admire, / Mon bras, qui tant de fois a sauvé cet empire, / Tant de fois affermi le trône et son roi, / Trahit donc ma querelle, et ne fait rien pour moi? (Le Cid, Acte I, Sc. 4)

26 Percés jusques au fond du coeur? / D'une atteinte imprévue aussi bien que mortelle, / Misérable vengeur d'une juste querelle / Et malheureux objet d'une injuste rigueur, / Je demeure immobile, et mon âme abattue / Cède au coup qui me tue. / Si près de voir mon feu récompensé, / O Dieu, l'étrange peine! / En cet affront mon père est l'offensé, / Et l'offenseur le père de Chimène! (Le Cid, Acte I, Sc. 6) 


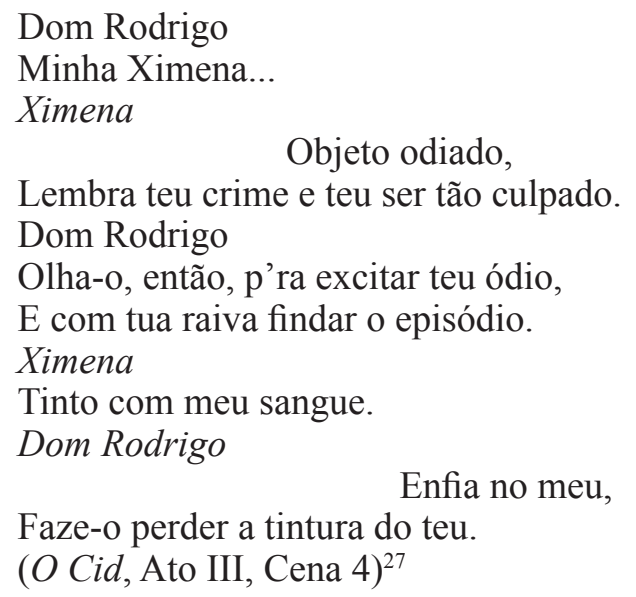

Alguns desses versos, cujas métricas só se completam na sucessão das falas do diálogo, realçam o caráter de jogo, de contracenar inerente ao texto dramático. Os atores têm que estar afinados, literalmente, baseando a atuação na justeza do ritmo, senão correm o risco de colocar tudo a perder.

E é nesse ponto específico que Novarina e Corneille podem se encontrar. Tanto no caso de um quanto no caso de outro, estamos no domínio da relação entre escrita e oralidade, que é o que caracteriza, em última instância, a chamada literatura dramática e que requer um árduo trabalho de composição, mesmo quando se assume o chamado tom coloquial.

\section{A prosa concreta de Nelson Rodrigues e de Plínio Marcos}

Sempre me pareceu indispensável que o ator que encara uma peça de Nelson Rodrigues, mestre do coloquial, tenha o sentido da métrica, perceba que o que rege as falas é o ritmo que vai se instaurando e não seu conteúdo. Não à toa, Nelson Rodrigues era conhecido por estabelecer em seus diálogos estranhas pontuações, como ponto final em frase que não se completa. E por não admitir "cacos" em seus espetáculos, pois as palavras eram escolhidas com propósitos muito bem determinados dentro daquela estrutura dramática. Outra característica marcante são as falas que não dialogam entre si de maneira direta ou que parecem apresentar respostas incongruentes.

Longe dos neologismos das partituras rítmico-sonoras de Novarina ou dos alexandrinos de Corneille, a prosa de Nelson Rodrigues obedece em sua composição ao mesmo rigor que caracteriza esses dois autores. Algo que pode passar despercebido, por assim dizer, pelo leitor ou pelo espectador. Mas que tem que ficar muito claro quando se tem a oportunidade de fazer um de seus personagens ou de traduzir um texto seu.

Meu percurso de tradutora começa em 1985 com as versões francesas de Senhora dos afogados e Doroteia, apresentadas em anexo à tese de doutorado que

27 Chimène - Hélas! Don Rodrigue - Écoute-moi. Chimène - Je me meurs. Don Rodrigue - Un moment. Chimène - Va, laisse-moi mourir. Don Rodrigue - Quatre mots seulement:/ Après, ne me réponds qu'avecque cette épée. Chimène - Quoi! du sang de mon père encor toute trempée! Don Rodrigue - Ma Chimène... Chimène - Ote-moi cet objet odieux, / Qui reproche ton crime et ta vie à mes yeux. Don Rodrigue - Regarde-le plutôt pour exciter ta haine, / Pour croître ta colère, et pour hâter ma peine. Chimène - II est teint de mon sang. Don Rodrigue - Plonge-le dans le mien / Et fais-lui perdre la teinture du tien. (Le Cid, Acte III, Sc. 4) 
defendi na universidade Paris I sobre o trágico no teatro de Nelson Rodrigues. Seguiram-se, ao longo dos anos, as de Valsa $n$. 6, A serpente, O beijo no asfalto, Toda nudez será castigada e, mais recentemente, Perdoa-me por me traíres, em parceria com o diretor francês Thomas Quillardet. ${ }^{28}$ É a partir de minha experiência traduzindo essas peças que vou comentar as característica acima citadas.

Valsa n. 6 é um exemplo privilegiado de como Nelson Rodrigues consegue compor uma partitura com sua prosa. Escrito em 1953, esse monólogo reúne características que perpassam todas as fases da obra do autor.

La jeune fille élevant progressivement la voix, jusqu'au cri.

Sonia !... Sonia !... Sonia !...

Pour elle-même

Qui est Sonia ?... Et où est Sonia?

Vite et effrayée

Sonia est ici, là-bas, partout!

Elle recule

Sonia, toujours Sonia...

Tout bas

Un visage m'accompagne... Et une robe... Et les sous-vêtements...

Elle regarde de tous les côtés; et vers le public, avec un demi-sourire.

Les sous-vêtements, oui,

Avec souffrance

Diaphanes, sans coutures...

Effrayée, accroupie à une des extrémités de la scène.

La robe qui me poursuit... A qui est-ce, mon Dieu?

Elle court, agile, vers l'avant-scène. Attitude polémique.

Mais je ne suis pas folle! (Déjà cordiale.) Bien sûr, évident!... Au contraire, j’ai toujours eu peur des fous!

Aimable, informe le public

Dans ma famille - Dieu merci - il n'y a jamais eu un seul cas de folie...

Elle crie, exultante

Des parents fous, je n'en ai pas!

Sans exaltation, humble et naïve

Seulement, je ne sais pas ce que je fais ici...

Regardant autour d'elle

$\mathrm{Ni}$ quel est cet endroit...

Elle recule, étonnée; elle serre son visage entre ses mains.

Des gens me regardent!

Elle regarde vers les côtés et vers le haut. Une plainte plus forte.

Mon Dieu, pourquoi y a-t-il tous ces yeux au monde?

Sans transition, frivole et cordiale

Après je me souviendrai de tout ce que j'ai été, de tout ce que je suis.

(Valse n. 6, Acte I) ${ }^{29}$

28 A tese foi posteriormente publicada no Brasil com o título Nelson Rodrigues, trágico, então moderno (Lopes, 1993; 2007). A tradução de Senhora dos afogados foi publicada em 1990 pela editora Christian Bourgois junto com a tradução de Valsa n. 6 (Rodrigues, 1990). Toda nudez será castigada e 0 beijo no asfalto foram publicadas num mesmo volume em 1999 pela editora Actes-Sud Papiers (Rodrigues, 1999). Perdoa-me por me traíres compõe o volume com a tradução realizada por Alexandra Moreira da Silva e Marie-Amélie Robilliard de A falecida, que foi editado pela editora Les Solitaires Intempestifs em 2016 (Rodrigues, 2016). As traduções de Doroteia e A serpente permanecem inéditas. Valsa n. 6, Toda nudez será castigada e 0 beijo no asfalto foram montadas por diretores como Alain Ollivier, Henri Ronse e Thomas Quillardet.

29 Mocinha (aumentando progressivamente a voz, até ao grito) Sônia!... Sônia!... Sônia!... (para si mesma) Quem é Sônia?... E onde está Sônia? (rápida e medrosa) Sônia está aqui, ali, em toda parte! (recua) Sônia, sempre Sônia... (baixo) Um rosto me acompanha... E um vestido.... E a roupa de baixo... (olha para os lados; e para a plateia, com meio riso) Roupa de baixo, sim, (com sofrimento) diáfana, inconsútil... (com medo, agachada numa das extremidades do palco) 0 vestido que me persegue... De quem será, meu Deus? (corre ágil, para a boca de cena. Atitude polêmica) Mas eu não estou louca! (já cordial) Evidente, natural!... Até, pelo contrário, sempre tive medo de gente doida! (amável e informativa, para a plateia) Na minha família - e graças a Deus - nunca houve um caso de loucura... (grita, exultante) Parente doido, não tenho! (sem exaltação, humilde e ingênua) Só não sei o que estou fazendo aqui... (olhando em torno) Nem sei que lugar é este... (recua, espantada; aperta o rosto entre as mãos) Tem gente me olhando! (olha para os lados e para o alto. Lamento maior) Meu Deus, por que existem 
Trata-se mais uma vez do pontapé inicial de uma partitura rítmica, que vai se instaurando aqui nessa alternância de falas e rubricas. Mais do que indicações para o ator ou complementos prosaico-poéticos à cena, essas notas entre as falas são como pausas no sentido da notação musical, realçando o tipo de composição da peça, dentro da qual a Valsa $n .6$ de Chopin não é um mero acompanhamento ou pano de fundo e sim um dos personagens, onipresente. Essa valsa vem também ajudar a criar o tempo muito particular da cena, repetitivo, circular. Fala e música enredam a personagem na eternidade de sua obsessão.

Em $O$ beijo no asfalto, talvez se tenha a expressão mais acabada das falas lacônicas e cortantes tão características das tragédias cariocas de Nelson Rodrigues. Impossível traduzir seus diálogos sem recriar sua pontuação específica como, por exemplo, na abertura da peça:

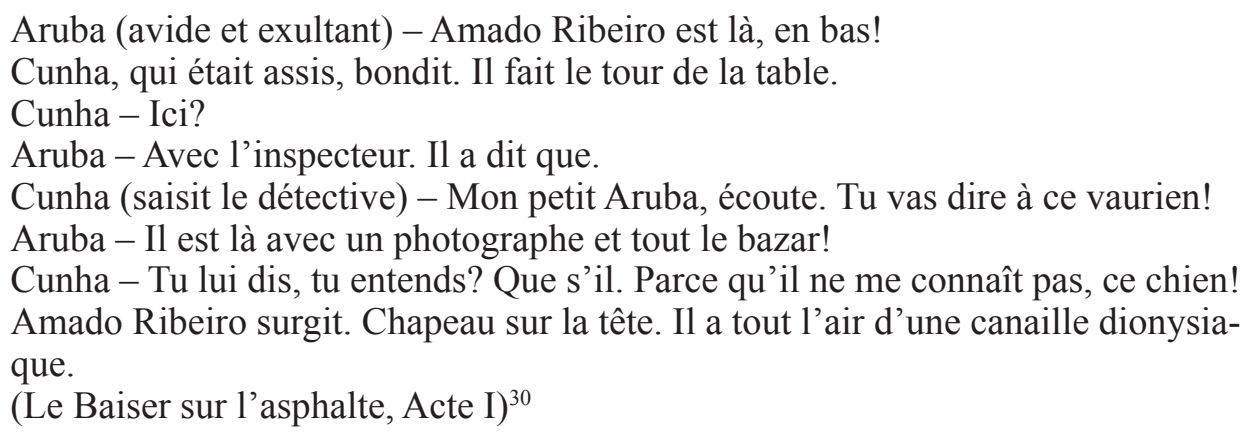

Mais do que um carioquismo que se costuma associar à obra de Nelson Rodrigues (2004) - afinal O beijo no asfalto é uma tragédia carioca -, esses diálogos mostram o quanto são laboriosamente burilados, até se transformar em partitura. $O$ ritmo das falas constitui obviamente o eixo do trabalho da tradução.

A partir daí, é só seguir as outras características do universo do autor, como o contraste que Nelson Rodrigues gosta de explorar entre o registro de linguagem e o contexto da cena. Exemplo disso é a extrema economia de palavras de baixo calão, mesmo quando a situação vivida pelos personagens já ultrapassou os limites da decência e da civilidade. Assim, em Senhora dos afogados, Moema chama sua mãe, D. Eduarda, de "prostituta" quando esta sai do quarto do bordel onde havia se entregado ao Noivo de sua filha. Pode parecer um erro do tradutor ou um certo pudor por parte do autor ligado à época em que o texto foi escrito - final dos anos 1940. Na verdade, há um forte impacto dramático produzido por esse contraste: a violência de uma filha jogar friamente na cara da mãe que ela é uma prostituta, contrariamente ao uso da palavra "puta", que pode ser decorrente de um ímpeto, de um momento de irreflexão.

São aspectos dessa ordem que a tradução das peças de Nelson Rodrigues traz à tona: a maneira como a escrita vai se armando e construindo oportunidades de

\footnotetext{
tantos olhos no mundo? (sem transição, frívola e cordial) Depois eu me lembro de tudo que fui, de tudo que sou. (Valsa n. 6, Ato I)

30 Aruba (sôfrego e exultante) - O Amado Ribeiro está lá embaixo! (Cunha, que estava sentado, dá um pulo. Faz a volta da mesa) Cunha - Lá embaixo? Aruba - Com o comissário. Disse que. Cunha (agarrando o detetive) - Arubinha, olha. Você vai dizer a esse moleque! Aruba - Está com fotógrafo e tudo! Cunha - Diz a ele, ouviu? Que se ele. Porque ele não me conhece, esse cachorro! (Amado Ribeiro aparece. Chapéu na cabeça. Tem toda a aparência de um cafajeste dionisíaco). (O beijo no asfalto, Ato I)
} 
contracenação. Caso análogo é o famoso "Água linda!" exclamado por Arandir, em 0 beijo no asfalto, quando vai matar sua sede após chegar em casa cansado depois de horas na delegacia. Ou ainda o diálogo a seguir de Perdoa-me por me traíres:

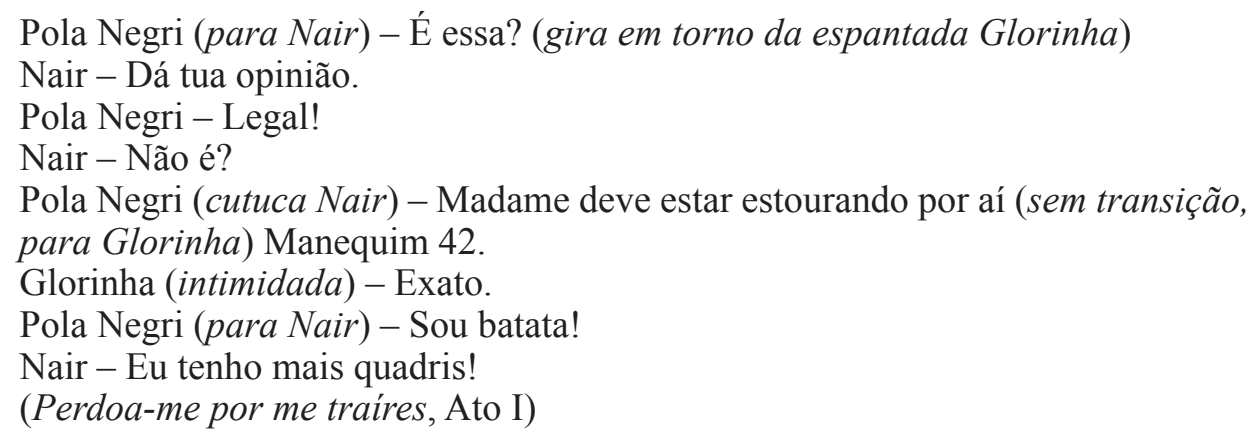

Uma fala aparentemente sem importância, a de Nair dizendo que tem mais quadris, é uma boa oportunidade para se voltar mais uma vez às considerações que venho desenvolvendo ao longo deste artigo. Não se trata de interpretar o que seria uma moça com "mais quadris", apenas fazê-la proferir essa frase. Algo que parecia, num primeiro momento, apresentar um problema para a versão em francês, mas que acabou acompanhando mesmo o original:

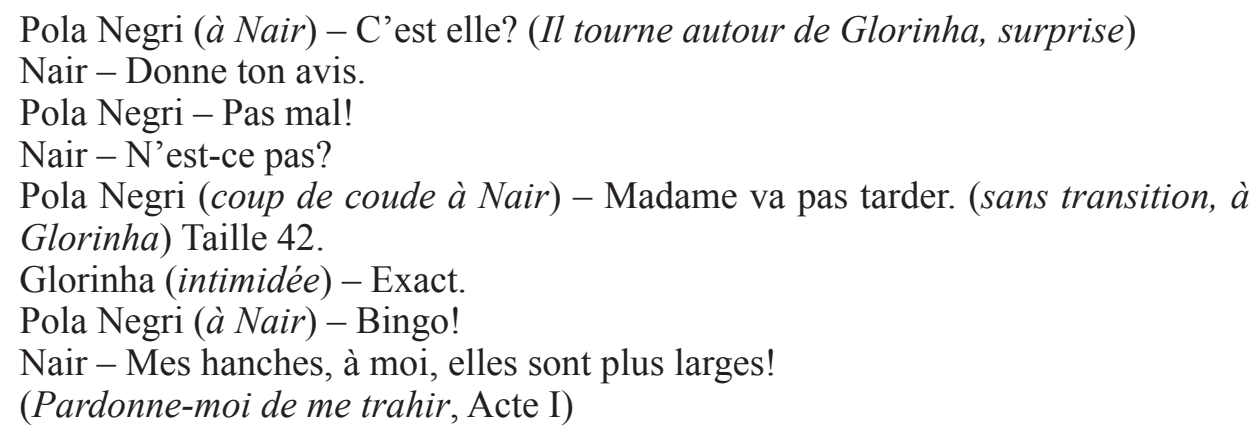

De todo modo, trata-se de uma fala que chama o gesto e o corpo, que estabelece de cara um contracenar, como Nelson Rodrigues sabia armar como ninguém. As interpretações são obviamente consequências desse fato. Optar por elas seria o mesmo que extinguir o caráter dramático (lembrando que drama significa ação) do texto.

Outro mestre do coloquial é Plínio Marcos. Em sua obra, há uma teia mais imbricada entre texto e contexto. Tive a oportunidade de traduzir Dois perdidos numa noite suja em 1998 para um projeto de Emílio de Mello e Thierry Trémouroux. ${ }^{31}$ Existia uma versão francesa realizada por Jacques Thiériot em 1974, que tinha permanecido inédita, mas era necessário fazer uma "atualização". Isso se deveu em grande parte à profusão de gírias e palavrões, característica do universo de Plínio Marcos, pois as expressões populares variam muito e de forma mais perceptível conforme as épocas. Jacques Thiériot havia já procurado fazer uma atualização quando traduziu, inserindo gírias no próprio título da peça: Deux paumés dans une nuit pourrie. Mas assim ele imprimiu logo de saída a conotação datada.

31 Houve uma leitura com Emílio de Mello e Thierry Trémouroux dirigida por Alain Ollivier no Salão do Livro de Paris em março de 1998 e outra dirigida por Michel Didym no Théâtre Gérard Philipe em Saint-Denis, na França em julho desse mesmo ano. 
Talvez seja difícil fugir desse dilema num tipo de produção textual como a de Plínio Marcos por essas suas características. Há, porém, ali também a composição precisa e muito firme de uma partitura. A obsessão dos dois personagens pelo par de sapatos de Paco produz um bordão que percute o ritmo da trama e vai servindo como uma espécie de guia nessa construção (Marcos, 1998).

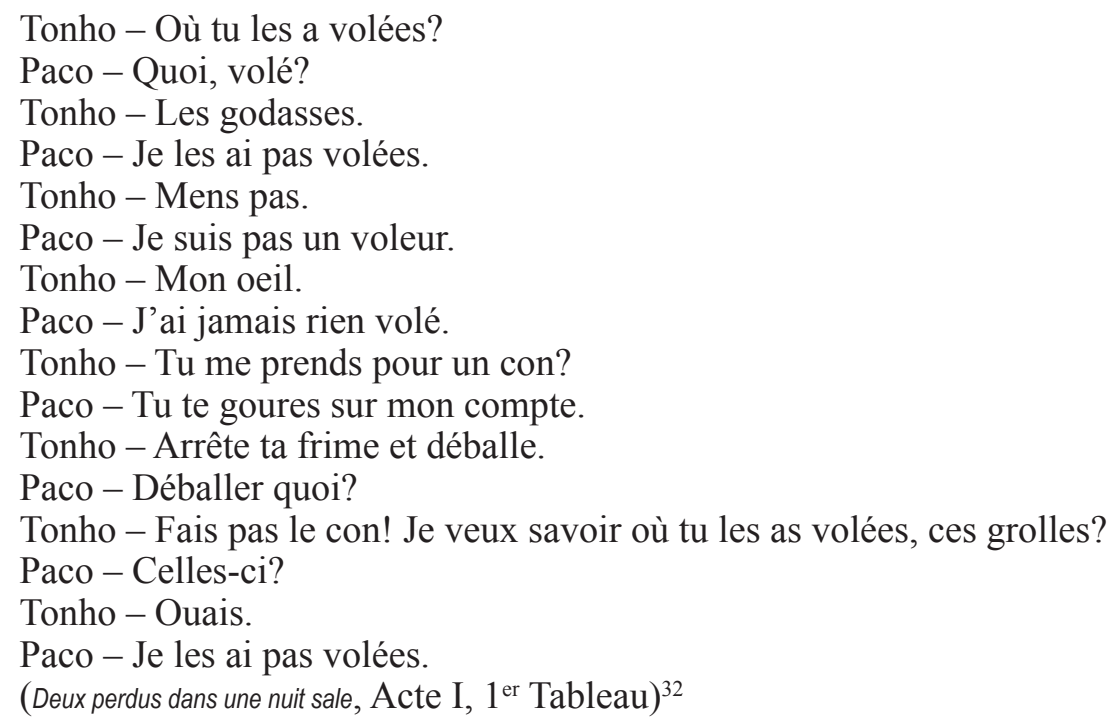

Isso não significa que minha tradução não venha a precisar ser por sua vez atualizada. Fui procurada um tempo atrás por Thomas Quillardet, que tinha o projeto de reeditar essa peça e achava que era preciso fazer uma revisão, pois afinal já se haviam passado 20 anos. O projeto, entretanto, não foi levado a cabo. Quando traduzi a peça, procurei optar por gírias mais próximas da época em que o texto tinha sido escrito (1966). Assim como meu intuito também foi procurar manter, na medida do possível, as aberturas de sentido presentes no original, como por exemplo no título: Deux perdus dans une nuit sale. Jacques Thiériot transformou "perdidos" no significado ao qual esse termo remete, o de paumés, que faz logo vir à mente a conotação de derrotados, pessoas sem rumo na vida. Preferi por minha vez deixar que a imaginação pudesse vagar no contato com perdus, que tem um significado mais abrangente, principalmente antes de se ter lido a peça. A mesma coisa se deu nas opções distintas para "suja": Jacques Thiériot optou por pourrie - podre, corrompida; e eu por sale - suja. Acredito ter acompanhado as premissas colocadas por Walter Benjamin e deixado alguma estranheza nessas minhas opções.

Essa necessidade de atualização aponta na verdade para outra questão que subjaz a toda criação literária: a do caráter dinâmico, vivo, da língua e, por conseguinte, do exercício da escrita. A língua vai mudando, de fato, com o tempo - o que não tem nada a ver com diferentes contextos de épocas. Temos aí, de todo modo, outro vasto campo de análise, que já não caberia aqui.

\footnotetext{
32 Tonho - Onde você roubou? Paco - Roubou o quê? Tonho - O sapato. Paco - Não roubei. Tonho - Não mente. Paco - Não sou ladrão. Tonho - Você não me engana. Paco - Nunca roubei nada. Tonho - Pensa que sou bobo? Paco - Você está enganado comigo. Tonho - Deixa de onda e dá o serviço. Paco - Que serviço? Tonho - Está se fazendo de otário? Quero saber onde foi que você roubou esses sapatos. Paco - Esses? Tonho - É. Paco - Mas eu não roubei. (Dois perdidos numa noite suja, Ato I, 10 Quadro)
} 


\section{Desafios}

O que move a escrita é sempre o desejo de escrever ainda ou de novo. Sendo assim, a escrita da tradução se inscreve justamente no espaço desse desejo recôndito de toda criação: o de estar sempre de fato por fazer. E, assim, vai acumulando desafios, pois tem que lidar com o texto original, as línguas, o tempo. E imprimir aí as suas próprias características de autoria.

\section{Referências}

BENJAMIN, Walter. A tarefa do tradutor. In: Escritos sobre mito e linguagem (19151921). Trad. Susana Kampff Lages. São Paulo: Editora 34/Duas Cidades, 2011.

BLANCHOT, Maurice.Traduzir. Trad. Angela Leite Lopes e Fátima Saadi. Folhetim. Rio de Janeiro, n.17, maio-ago. 2003.

BLANCHOT, Maurice.. Traduire. In: L'Amitié. Paris: Gallimard, 1971.

CORNEILLE, Pierre. O Cid. 2 ed. Trad. Angela Leite Lopes. Rio de Janeiro: 7Letras, 2013.

CORNEILLE, Pierre. Le Cid (1636-1637). Oeuvres complètes. Paris: Seuil, 1963.

LOPES, Angela Leite. Valère Novarina e o viveiro das línguas. In: LOPES, Angela Leite; TORRES NETO, Walter Lima (org.). Teatro em francês: quando o meio não é a mensagem. Curitiba: Ed. UFPR, 2018.

LOPES, Angela Leite. Traduzindo Novarina - cena, pintura e pensamento. Rio de Janeiro: 7Letras, 2017.

LOPES, Angela Leite. O tempo em verso. In: CORNEILLE, Pierre. O Cid. 2 ed. Trad. Angela Leite Lopes. Rio de Janeiro: 7Letras, 2013.

LOPES, Angela Leite. Cesura e suspensão na cena de Novarina. In: LOPES, Angela Leite (org.). Novarina em cena. Rio de Janeiro: 7Letras/Faperj, 2011.

LOPES, Angela Leite. Nelson Rodrigues, trágico, então moderno. Rio de Janeiro: Nova Fronteira, 2007.

LOPES, Angela Leite. O ator e a interpretação. Folhetim. Rio de Janeiro, n. 6, jan.-abr. 2000, p.64-73.

LOPES, Angela Leite. Nelson Rodrigues, trágico, então moderno. Rio de Janeiro: Ed. UFRJ/Tempo Brasileiro, 1993. 
MARCOS, Plínio. Deux perdus dans une nuit sale. Trad. Angela Leite Lopes. Rio de Janeiro: Funarte, 1998.

NOVARINA, Valère. O monólogo de Adramelech. Trad. Angela Leite Lopes. Inédito, 2019.

NOVARINA, Valère. Le Monologue d'Adramélech. Paris: P.O.L, 2009a.

NOVARINA, Valère. O ateliê voador e Vocês que habitam o tempo. Trad. Angela Leite Lopes. Rio de Janeiro: 7Letras, 2009b.

NOVARINA, Valère. Le Théâtre des paroles. Paris: P.O.L, 2007a.

NOVARINA, Valère. O animal do tempo e A inquietude. Trad. Angela Leite Lopes. Rio de Janeiro: 7Letras, 2007b.

NOVARINA, Valère. Carta aos atores e Para Louis de Funès. Trad. Angela Leite Lopes. Rio de Janeiro: 7Letras, 1999.

NOVARINA, Valère. L'Inquiétude. Paris: P.O.L, 1993.

NOVARINA, Valère. Vous qui habitez le temps. Paris: P.O.L, 1989.

RACINE, Jean. Fedra. 2 ed. Trad. Millôr Fernandes. Porto Alegre: L\&PM, 1986.

RACINE, Jean. Phèdre. In: Oeuvres complètes. Paris: Seuil, 1962.

RODRIGUES, Nelson. La Défunte, suivi de Pardonne-moi de me trahir. Trad. de Alexandra Moreira da Silva, Marie-Amélie Robbilliard, Angela Leite Lopes et Thomas Quillardet. Besançon: Les Solitaires Intempestifs, 2016.

RODRIGUES, Nelson. Teatro completo. V.1-4. 2 ed. Rio de Janeiro: Nova Fronteira, 2004.

RODRIGUES, Nelson. Toute nudité sera châtiée, suivi de Le Baiser sur l'asphalte. Trad. Angela Leite Lopes. Paris: Actes-Sud Papiers, 1999.

RODRIGUES, Nelson. Valse n. 6, suivi de Dame des noyés. Trad. Angela Leite Lopes. Paris: Christian Bourgois, 1990.

Enviado em: 16/08/2019

Aprovado em: 30/08/2019 